\title{
A Pythagorean Fuzzy Approach for Sustainable Supplier Selection Using TODIM
}

\author{
Prabjot Kaur $\mathbb{D}^{1},{ }^{1}$ Vaishnudebi Dutta $\mathbb{D D}^{1},{ }^{1}$ Bijay Lal Pradhan $\mathbb{D}^{2},{ }^{2}$ Subhomoy Haldar $\mathbb{D}^{1}$, \\ and Supriya Chauhan' \\ ${ }^{1}$ Department of Mathematics, Birla Institute of Technology, Mesra, Ranchi, Jharkhand, India \\ ${ }^{2}$ Department of Statistics, Amrit Campus, Tribhuvan University, Kathmandu, Nepal \\ Correspondence should be addressed to Bijay Lal Pradhan; bijaya.pradhan@ac.tu.edu.np
}

Received 12 August 2021; Revised 19 September 2021; Accepted 5 October 2021; Published 23 October 2021

Academic Editor: Yuvraj Gajpal

Copyright (C) 2021 Prabjot Kaur et al. This is an open access article distributed under the Creative Commons Attribution License, which permits unrestricted use, distribution, and reproduction in any medium, provided the original work is properly cited.

\begin{abstract}
Several firms have become increasingly concerned with sustainability in recent decades and are thus implementing environmental and social changes in their businesses and supply networks. This article aims to assess suppliers based on green design, corporate social responsibility, energy consumption, and other sustainability factors that might aid the growth of a company. Characteristics used in this study will help to accomplish economic, environmental, and social responsibility for organizations to reduce global warming and natural resource depletion. We have used the data given in the article of Zolfani et al. by implementing Pythagorean fuzzy TODIM (an acronym in Portuguese for iterative multicriteria decision making) to calculate the rank of suppliers based on the Triple Bottom Line (TBL) sustainability framework. Both TODIM and PF-TODIM are simple to compute, stable, consistent, and accurate, but we have proved by calculations why Pythagorean fuzzy TODIM should be chosen over TODIM in such situations, where decision makers do not have access to a reliable data source. Finally, we performed a sensitivity analysis on both TODIM and PF-TODIM, and the results bolstered the utility of the model.
\end{abstract}

\section{Introduction}

In the management of a supply chain, supplier selection is critical. The goal is to find a supplier who can provide the finest product or service for the least amount of money. Proper supplier selection results in a high level of profit and quality. In this strategic partnership, the supplier is considered as an important part of the business. Selection of these suppliers has become more difficult because of the recent emphasis on sustainability. Studies on environmental protection, also known as studies related to sustainability, have grown significantly across the world. Because of the new focus on sustainability, finding these suppliers has grown increasingly challenging. Environmental studies, or studies on sustainability, have exploded in popularity across the world Lee et al. [1]. Consumer and client knowledge of sustainability has increased tremendously, affecting how goods and services are created and provided. As a result, the concept of a sustainable supply chain emerged, attracting academic and industrial interest from both public and private organisations studied by Büyükozkan and Çifçi [2]. There are several other related research articles based on supply chain such as those of Bhatia et al. [3], which enlighten us with Mehar approach for finding the shortest path in the supply chain network. [4]

One of the most crucial aspects of long-term supply chain management is supplier selection. Articles written by Büyükozkan and Çifçi [2], Nielsen et al. [5], and El Mariouli and Abouabdellah [6] include the coordination of all operations required in the management of the supply chain. As a result, instead of focusing on conventional criteria like cost, quality, or delivery, companies choose to focus on the "Triple Bottom Line" (TBL) approach for supplier assessment and selection. So, sustainability has become a term in the business world, and it is defined as development that satisfies current demands without jeopardising future 
generations' capacity to satisfy their own (WCED, 1987) [7]. When choosing sustainable suppliers, economic, environmental, and social aspects are all considered.

Many approaches for sustainable supplier selection have been developed because of the necessity of sustainable supply chain management. Thus, decision-supporting models can help a business achieve a competitive advantage as described in several articles, and some of them are those of Genovese et al. [8], Govindan et al. [9], Igarashi et al. [10], and Nielsen et al. [5]. Batista Schramm et al. [11] performed their research using popular databases, such as SCOPUS, to perform descriptive analytical studies. They discovered that when one strategy is applied individually, the most common ones are DEA (mathematical programming technique), TOPSIS, and AHP. The uncertainty of human-like knowledge in sustainability criteria is assessed using a mix of MCDM and fuzzy set theory in sustainable supplier selection. TOPSIS and fuzzy TOPSIS are the most commonly used MCDM methods; Shalke et al. [12], Mohammed [13], and Memari et al. [14] implemented fuzzy TOPSIS in their model to account for imprecision in judgments; Bai and Sarkis [15] did their analysis using TOPSIS with Grey Theory to deal with imprecision. They also shared research on the grey system and rough set technique. Bai and Sarkis [16] used Rough Set Theory to cope with uncertainties and imprecision, whereas Li et al. [17] used the Entropy Measure Method and Grey Correlation Study. dos Santos et al. [18] utilized a fuzzy approach of TOPSIS that aggregated Shannon's Entropy to introduce uncertainty to the study. Some of the other notable works include Luthra et al. [19], Jain and Singh [20], Zhao et al. [21], Jain et al. [22], Jain and Singh [23], and Qin et al. [24] where we see various MCDM approaches especially implemented in the substantiable supplier selection process.

Sarkis [25] used the analytical network process (ANP) to examine the influence of various organisational options on important environmentally conscious corporate practises. Galankashi et al. [26] used a fuzzy ANP method to choose green suppliers. For sustainable supplier selection and order allocation in the automobile sector, Khoshfetrat et al. [27] created a fuzzy, multiobjective, multiproduct, multiperiod mathematical model. Tavana et al. [28] used the ANP-QFD framework to solve the challenge of sustainable supplier selection, whereas Okwu and Tartibu [29] proposed a TOPSIS and ANFIS-based method to the problem of long-term supplier selection. Several other combined methods, such as fuzzy best worst method- fuzzy interference system (FBWM-FIS) - a hybrid fuzzy approach was used by Hoseini et al. [30] in Sustainable Supplier Selection (SSS) for construction industry, to simulate decision-making process for dealing with large number of criteria. Akman [31] utilised other MCDM techniques, such as VIKOR, while assessing suppliers to incorporate green supplier development plans using Fuzzy C Means. Almasi et al. [32] developed a multiobjective sustainable supplier selection and order allocation model that accounts for risk and inflation.
The findings of a TODIM (TOmada de Deciso Interativa e Multicritério-an acronym in Portuguese for iterative multicriteria decision making) MCDM technique are presented in this article. We utilised TODIM with Fuzzy Pythagorean Numbers to test both the findings and the rankings in a fuzzy environment, using the Rank Sum Method to calculate the weights of criteria. Authors like Gomes and Rangel [33] studied in their paper how the TODIM method constitutes efficient support for the evaluation of property. Mao et al. [34] used a hybrid method to assess a heterogeneous framework for sustainable supplier evaluation and selection, using interval-valued intuitionistic fuzzy TODIM (IVIF-TODIM). Khamesh [35] also looked at an integrated sustainable-flexible multicriteria model based on TODIM, which incorporated both gain and loss of decision and utilised prospect theory to account for uncertainty, whereas Bai et al. [36] used grey-BWM for attribute weights and grey TODIM to rank suppliers. From the perspective of sustainability, Table 1 contains a simplified list of publications where different MCDM methods were employed.

The data supplied to decision makers is not always clear or precise, due to which we depend on a fuzzy approach. The calculations and the methodology Pythagorean fuzzy TODIM shown in this article is not only accurate but also easier to grasp and compute than other methods such as improved TOPSIS studied by Tian et al. [37] or IF-TOPSIS studied by Memari et al. [14] or even IF-VIKOR studied by Abdel-Baset et al. [38]. We have also included the Python code at the conclusion of this article, which is freely accessible on our Github profile, so that researchers, academicians, and anybody else may use for their research purposes because sensitivity analysis software is not readily available. Theoretical contribution of our model is that we validated the PF-TODIM and shown through sensitivity analysis that it outperforms TODIM in riskier and more unpredictable environments for sustainable supplier selection. The Pythagorean Fuzzy method was selected because it may be considered a superset of the Triangular Fuzzy set, and the method is also relatable with the concept of intuitionistic fuzzy sets. This is the novelty of the Pythagorean Fuzzy method over the existing TODIM method. We selected the rank sum weight approach in our study because it provides decision makers greater flexibility in determining the relevance of criteria, and it is also easier to use and understand.

A case study of an Iranian steel company is used in our article to show the relevance and suitability of the recommended sustainability decision framework. Our aim is to answer the following in this article:

(1) What is the application of Pythagorean fuzzy TODIM?

(2) Why is TODIM in fuzzy environments more promising than TODIM on crisp sets?

(3) How sure can decision makers be about the ranks of the alternatives? 
TABLE 1: Literature on multicriteria decision-making (MCDM) application based on sustainability perspective.

\begin{tabular}{lc}
\hline Publications & Methods used \\
\hline Bojković et al. [39] & Modified ELECTRE \\
Majdi [40] & PROMETHEE and ELECTRE \\
Guo and Zhao [41] & Fuzzy TOPSIS \\
Micale et al. [42] & ELECTRE III \\
Awasthi et al. [43] & Fuzzy AHP-VIKOR \\
Chen and Ren [44] & Fuzzy ANP and fuzzy grey relational analysis \\
Suganthi [45] & Integrated fuzzy AHP, VIKOR/DEA \\
Wang et al. [46] & Hybrid fuzzy AHP \\
Nilashi et al. [47] & Hybrid TOPSIS-neuro fuzzy environment \\
Tang et al. [48] & Modified TOPSIS based on grey relational analysis \\
Du et al. [49] & Intuition fuzzy AHP-TODIM \\
Peng et al. [50] & Fuzzy exponential entropy, and extended VIKOR \\
Wu et al. [51] & DEMATEL-entropy TODIM \\
Alimohammadlou and Khoshsepehr [52] & Fuzzy decision-making framework based on full consistency method and fusion ranking model \\
Tang et al. [53] & Interval-valued intuitionistic fuzzy AHP and WASPAS \\
\hline
\end{tabular}

(4) What are the future scopes and how the researchers can be benefited?

All the abovementioned questions are answered in this article following the implementation of the model, sensitivity analysis, and discussion of future research possibilities.

\section{Preliminaries}

2.1. Pythagorean Fuzzy Sets and Pythagorean Fuzzy Numbers. The concept of Pythagorean fuzzy sets (PFS) was pioneered by Yager [54], to deal with vagueness with the membership grades as pairs satisfying the conditions of membership and nonmembership degree. We refer to Ren and Gou [55] for the definitions used and properties listed.

Let a set $X$ be a universal set, then the PFS $P$ is a mathematical object defined as

$$
\begin{aligned}
P & =\left\{\left\langle x, P\left(\mu_{p}(x), v_{p}(x)\right)\right\rangle \mid x \in X, 0\right. \\
& \left.\leq\left(\mu_{p}(x)\right)^{2}+\left(v_{p}(x)\right)^{2} \leq 1\right\},
\end{aligned}
$$

where $\mu_{p}$ represents the degree of membership and $v_{p}$ represents the degree of nonmembership of $x$ in $P$. For the ease of using in programming applications, the definition of a Pythagorean Fuzzy Number (PFN) is

$$
\beta=P\left(\mu_{\beta}, v_{\beta}\right),
$$

where $\mu_{\beta}, v_{\beta} \in[0,1]$ and $\mu_{\beta}^{2}+v_{\beta}^{2} \leq 1$.

2.2. Operations on PFNs and Additional Functions. Besides $\mu_{p}$ and $\nu_{p}$, PFNs have the following properties:

(1) Hesitant degree: $\pi_{\beta}=\sqrt{1-\mu_{\beta}^{2}-v_{\beta}^{2}}$.

(2) Score value: $s(\beta)=\mu_{\beta}^{2}-v_{\beta}^{2}$.

(3) Accuracy value: $h(\beta)=\mu_{\beta}^{2}+v_{\beta}^{2}$.

(4) Euclidean distance between two PFNs $\beta_{1}$ and $\beta_{2}$ :

$$
d\left(\beta_{1}, \beta_{2}\right)=\sqrt{\frac{1}{2}\left(\left(\mu_{\beta_{1}}^{2}-\mu_{\beta_{2}}^{2}\right)^{2}+\left(\nu_{\beta_{1}}^{2}-\nu_{\beta_{2}}^{2}\right)^{2}+\left(\pi_{\beta_{1}}^{2}-\pi_{\beta_{2}}^{2}\right)^{2}\right)} .
$$

The relevant mathematical operations (among others) on PFNs are as follows:

(1) Negation or complement $\beta^{c}=P\left(v_{p}, \mu_{p}\right)$

(2) Comparison of two PFNs $\beta_{1}$ and $\beta_{2}$ defined in the following manner:

(i) If $s\left(\beta_{1}\right)<s\left(\beta_{2}\right)$, then $\beta_{1}<\beta_{2}$ (and vice versa)

(ii) If $s\left(\beta_{1}\right)=s\left(\beta_{2}\right)$, then

$$
\begin{aligned}
& \text { If } h\left(\beta_{1}\right)<h\left(\beta_{2}\right), \text { then } \beta_{1}<\beta_{2} \\
& \text { If } h\left(\beta_{1}\right)=h\left(\beta_{2}\right) \text {, then } \beta_{1}=\beta_{2} \\
& \text { If } h\left(\beta_{1}\right)>h\left(\beta_{2}\right), \text { then } \beta_{1}>\beta_{2}
\end{aligned}
$$

\section{Methodology for Solving Sustainable Supplier Selection Problem}

3.1. The TODIM Method. The traditional TODIM algorithm, based on crisp numbers, is based on nonlinear CPT $(\mathrm{Cu}-$ mulative Prospect Theory) because its value function is identical to Tversky and Kahneman [56] CPT gain/loss function. Gains and losses are always calculated in relation to a reference point in this situation. As a result, although this method recognizes the possibility of decision makers, it does not account for their actual participation.

We start with the ratings as crisp (regular, nonfuzzy) numbers in the matrix $\left(x_{i j}\right)_{m \times n}$. The alternatives are $A_{i}$, the criteria are $C_{j}$. Here, $i=1,2, \ldots, m ; j=1,2, \ldots, n$.

Step 1: we normalize the ratings and weights using the formula:

$$
P_{i j}= \begin{cases}\frac{x_{i j}}{\sum_{k=1}^{m} x_{k j}}, & \text { if } j \in J_{1}, \\ \frac{\left(1 / x_{i j}\right)}{\sum_{k=1}^{m}\left(1 / x_{k j}\right)}, & \text { if } j \in J_{2} .\end{cases}
$$


For the weighting factor or trade-off rate between the reference criteria $r$ and the generic criteria $c$. In this case, $w_{r}$ determines the most relevant reference criterion for the decision maker. Often, is it the maximum weight. In general, any criterion can be used as the reference criterion, and this decision has no effect on the final findings. So, the formula we have

$$
w_{r c}=\frac{w_{c}}{w_{r}}
$$

where $\quad w_{r}=\max \left\{w_{c} \mid c=1,2, \ldots, n\right\} \quad$ and $i=1,2 \ldots, m ; j=1,2 \ldots, n$.

Step 2: for calculating the dominance degree, we need to first check the contribution of each criteria using the formula, where $\varphi_{c}$ is the contribution of criterion $c$ to the function $\delta\left(A_{i}, A_{j}\right)$ and $\theta$ is the loss of attenuation factor whose value, we considered as 2.5 in our case. The value is chosen so because it is the median value in the range $(0,5]$. Too small a value increases the sensitivity, whereas too big a value reduces the sensitivity. We perform further sensitivity analysis later on.

$$
\varphi_{c}\left(A_{i}, A_{j}\right)= \begin{cases}\sqrt{\frac{\left(P_{i c}-P_{j c}\right) w_{r c}}{\sum_{c=1}^{n} w_{r c}},} & \text { if } P_{i c}-P_{j c} \geq 0, \\ -\frac{1}{\theta} \sqrt{\frac{\left(\sum_{c=1}^{n} w_{r c}\right)\left(P_{j c}-P_{i c}\right)}{w_{r c}}}, & \text { if } P_{i c}-P_{j c}<0 .\end{cases}
$$

Combining all contributions, we get the dominance degrees from the measurement of dominance $\delta\left(A_{i}, A_{j}\right)$ as

$$
\delta\left(A_{i}, A_{j}\right)=\sum_{c=1}^{n} \varphi_{c}\left(A_{i}, A_{j}\right)
$$

where $i, j=1,2 \ldots, m ; c=1,2 \ldots, n$.

Step 3: finally, compute the values of $\xi_{i}$, which are the normalised global performances of alternatives in comparison to others, such that the largest value is picked as more significant than the value of other alternatives:

$$
\xi_{i}=\frac{\sum_{j=1}^{n} \delta\left(A_{i}, A_{j}\right)-\min _{i} \sum_{j=1}^{n} \delta\left(A_{i}, A_{j}\right)}{\max _{i} \sum_{j=1}^{n} \delta\left(A_{i}, A_{j}\right)-\min _{i} \sum_{j=1}^{n} \delta\left(A_{i}, A_{j}\right)},
$$

where $i=1,2, \ldots, n$.

3.2. Pythagorean Fuzzy TODIM. In contrast to the normal version, the decision matrix is represented as $R=\left(r_{i j}\right)_{m \times n}$.

$$
R=\left[\begin{array}{cccc}
P\left(\mu_{11}, v_{11}\right) & P\left(\mu_{12}, v_{12}\right) & \ldots & P\left(\mu_{1 n}, v_{1 n}\right) \\
P\left(\mu_{21}, v_{21}\right) & P\left(\mu_{22}, v_{22}\right) & \ldots & P\left(\mu_{2 n}, v_{2 n}\right) \\
\vdots & \vdots & \ldots & \vdots \\
P\left(\mu_{m 1}, v_{m 1}\right) & P\left(\mu_{m 2}, v_{m 2}\right) & \ldots & P\left(\mu_{m n}, v_{m n}\right)
\end{array}\right],
$$

where criteria are along the row and alternatives along the column. We follow the steps as follows:
Step 1: we create a Pythagorean decision fuzzy matrix $R=\left(r_{i j}\right)_{m \times n}$, given by the decision maker.

Step 2: we convert this decision matrix into a normalized decision matrix $L=\left(l_{i j}\right)_{m \times n}$ as

$$
l_{i j}= \begin{cases}r_{i j}, & j \in J_{1}, \\ \left(r_{i j}\right)^{c}, & j \in J_{2},\end{cases}
$$

where $r_{i j}$ is for benefit criteria and $\left(r_{i j}\right)^{c}$ is for the cost criteria.

Step 3: we then compute the relative weight of each criterion as $w_{j r}=w_{j} / w_{r}$, where $w_{j}$ is the weight of criteria $C_{j}$ and $w_{r}=\max \left\{w_{j} \mid j=1,2, \ldots, n\right\}$.

Step 4: the degree of dominance of each alternative $A_{i}$ is then calculated over $A_{j}$ with respect to criterion $C_{j}$ by

$$
\varphi_{c}\left(A_{i}, A_{j}\right)= \begin{cases}\sqrt{\frac{d\left(l_{i c}, l_{c j}\right) w_{r c}}{\sum_{c=1}^{n} w_{r c}},} & \text { if } P_{i c} \geq P_{j c}, \\ -\frac{1}{\theta} \sqrt{\frac{\left(\sum_{c=1}^{n} w_{r c}\right) d\left(l_{i c}, l_{c j}\right)}{w_{r c}},} & \text { if } P_{i c}<P_{j c},\end{cases}
$$

where $\theta$ is the loss attenuation factor and $d\left(l_{i c}, l_{c j}\right)$ is the distance between the PFN $l_{i c}$ and $l_{c j}$.

Step 5: we then compute the overall dominance degree using formula (7): 


$$
\delta\left(A_{i}, A_{j}\right)=\sum_{c=1}^{n} \varphi_{c}\left(A_{i}, A_{j}\right)
$$

Step 6: we then determine the overall value of each alternative $A_{i}$ by formula (8)

$$
\xi_{i}=\frac{\sum_{j=1}^{m} \delta\left(A_{i}, A_{j}\right)-\min _{i}\left\{\sum_{j=1}^{m} \delta\left(A_{i}, A_{j}\right)\right\}}{\max _{i}\left\{\sum_{j=1}^{m} \delta\left(A_{i}, A_{j}\right)\right\}-\min _{i}\left\{\sum_{j=1}^{m} \delta\left(A_{i}, A_{j}\right)\right\}} .
$$

Each alternative may be ranked according to the notion, that is, the more the overall value $\xi_{i}$, the better the alternative $A_{i}$.

Step 7: the alternatives are then ranked based on their overall values.

3.3. Rank Sum Weighting Algorithm. Zoraghi et al. [57] said that the subjective method establishes weights solely based on the decision makers' considerations or judgments. It may be easier to describe alternative inexact weights, such as bounded weights, by ranking order the significance of criteria. Time constraints, the nature of the criterion, a lack of expertise, inaccurate, incomplete, or partial data, and the decision maker's limited attention and information processing abilities, for example, are all variables to consider. Because a group of decision makers may not agree on a set of specific weights, as Roszkowska [58] indicates, it may be reasonable to assume agreement on a weight ranking. This approach includes two steps: first, rating the criteria by significance and then weighting the criteria using the formula. The rank sum weight technique, which we used in our research, was proposed by Stillwell et al. [59]. In the rank sum (RS) approach, individual ranks are normalized by dividing the total of the rankings. The weights are calculated using the following formula:

$$
w_{j}(R S)=\frac{2\left(n+1-r_{j}\right)}{n(n+1)},
$$

where $r_{j}$ is the rank of the $j$ th criteria, $j=1,2, \ldots, n$.

\section{Numerical Example}

A Supplier Selection dataset for Alborz company in Iran is taken from Zolfani et al. [4]. The criteria for the evaluation are presented in Table 2. The crisp dataset of scores for the alternatives is presented in Table 3 . The data comprise six suppliers being evaluated on seven criteria. We apply TODIM for the evaluation and selection of suppliers. For Pythagorean fuzzy TODIM, we make use of the modified data presented in Table 4.

\subsection{Regular TODIM}

(1) First, we normalise the data we have on the suppliers. We also renormalise the weights.
TABLE 2: The criteria used for evaluation, their ranks, and weights.

\begin{tabular}{lcccc}
\hline Criteria & Name & Rank & Ideally & Weights \\
\hline Price & Price & 3 & Lower & 0.178571 \\
Quality & Quality & 5 & Higher & 0.107143 \\
EC & Energy consumption & 2 & Lower & 0.214286 \\
GD & Green design & 1 & Higher & 0.250000 \\
DS & Delivery speed & 6 & Higher & 0.071429 \\
CSR & Corporate social & 4 & Higher & 0.142857 \\
EE & responsibility & 7 & Higher & 0.035714 \\
\hline
\end{tabular}

TABLE 3: Crisp scores for alternatives.

\begin{tabular}{lccccccc}
\hline Name & Price & Quality & EC & GD & DS & CSR & EE \\
\hline S1 & 10 & 4 & 8 & 10 & 2 & 0.7 & 8 \\
S2 & 4 & 2 & 6 & 8 & 2 & 0.75 & 6 \\
S3 & 1 & 1 & 8 & 6 & 2 & 0.65 & 6 \\
S4 & 10 & 10 & 8 & 10 & 8 & 0.85 & 8 \\
S5 & 2 & 4 & 6 & 6 & 2 & 0.75 & 6 \\
S6 & 10 & 6 & 8 & 8 & 8 & 0.85 & 8 \\
\hline
\end{tabular}

(2) Next, we compare each pair $\left(A_{i}, A_{j}\right)$ with respect to all criteria, keeping in mind the attenuation factor $\theta=2.5$ to generate the $\phi$ values.

(3) We congregate the $\phi$ values for every category to calculate the $\delta$ values for each pair. The calculated $\delta$ matrix is shown in Table 5 .

(4) We make use of the $\delta$ values to generate the $\xi_{i}$ value for each alternative $A_{i}$, which are listed in Table 6.

(5) We rank the alternatives based on the $\xi_{i}$ values, in decreasing order of preference.

Therefore, ranking the candidates using normal TODIM, we get

$$
S_{4}>S_{6}>S_{1}>S_{5}>S_{2}>S_{3}
$$

\subsection{Pythagorean Fuzzy TODIM}

(1) We consider the fuzzy responses of the decision makers on the scores of each alternative on every criterion and convert them to normalised Pythagorean Fuzzy Numbers.

(2) We take the complement of a PFN if the criterion is unfavourable.

(3) The weights are normalised. We can reuse the weights we calculated in the previous section.

(4) We generate the $\phi$ values for every pair and very criteria.

(5) We use the $\phi$ values to calculate the dominance degrees $\delta$ for all the pairs, which are displayed in Table 7 .

(6) Using the $\delta$ values we calculate the rating $\xi_{i}$, listed in Table 8. 
TABLE 4: Fuzzy scores for alternatives.

\begin{tabular}{lccccccc}
\hline Name & Price & Quality & EC & GD & DS & CSR & EE \\
\hline S1 & $(0.085,0.01)$ & $(0.68,0.08)$ & $(0.6375,0.075)$ & $(0.8,0.1)$ & $(0.2125,0.025)$ & $(0.7,0.08)$ & $(0.85,0.1)$ \\
S2 & $(0.2125,0.025)$ & $(0.17,0.02)$ & $(0.85,0.1)$ & $(0.64,0.08)$ & $(0.2125,0.025)$ & $(0.75,0.08)$ & $(0.6375,0.075)$ \\
S3 & $(0.85,0.1)$ & $(0.085,0.01)$ & $(0.6375,0.075)$ & $(0.51,0.06)$ & $(0.2125,0.025)$ & $(0.65,0.076)$ & $(0.6375,0.075)$ \\
S4 & $(0.085,0.01)$ & $(0.85,0.1)$ & $(0.6375,0.075)$ & $(0.85,0.1)$ & $(0.8,0.1)$ & $(0.85,0.1)$ & $(0.85,0.1)$ \\
S5 & $(0.425,0.05)$ & $(0.34,0.04)$ & $(0.85,0.1)$ & $(0.51,0.06)$ & $(0.2125,0.025)$ & $(0.75,0.08)$ & $(0.6375,0.075)$ \\
S6 & $(0.065,0.01)$ & $(0.51,0.061)$ & $(0.6375,0.075)$ & $(0.68,0.08)$ & $(0.85,0.1)$ & $(0.85,0.1)$ & $(0.85,0.1)$ \\
\hline
\end{tabular}

TABLE 5: $\delta$ matrix for regular TODIM.

\begin{tabular}{lcccccc}
\hline & $S 1$ & $S 2$ & $S 3$ & $S 4$ & $S 5$ & -1.171015 \\
\hline$S 1$ & 0.000000 & -0.327819 & -0.292882 & -1.516551 & -0.536707 & -0.561087 \\
S2 & -0.700333 & 0.000000 & -0.247943 & -1.977770 & -2.088571 & -0.548755 \\
$S 3$ & -0.931105 & -0.492989 & 0.000000 & 0.000000 & -0.081800 & -1.841270 \\
$S 4$ & 0.356560 & 0.061872 & -0.039756 & -1.883937 & 0.000000 & -1.572823 \\
S5 & -0.363026 & 0.073358 & -0.198827 & -0.633655 & -0.189292 & 0.000000 \\
S6 & 0.128045 & -0.092376 & -0.130155 & &
\end{tabular}

TABLE 6: Ratings using regular TODIM.

\begin{tabular}{lc}
\hline & $\xi_{i}$ \\
\hline$S 1$ & 0.320137 \\
S2 & 0.123827 \\
S3 & 0.000000 \\
S4 & 1.000000 \\
S6 & 0.304535 \\
\hline
\end{tabular}

(7) Finally, we generate the ranking of the alternatives using the ratings. They are listed in descending order of preference.

The rankings using Pythagorean fuzzy TODIM are

$$
S_{4}>S_{6}>S_{1}>S_{2}>S_{5}>S_{3} \text {. }
$$

Supplier 4 (S4) is the best supplier among the others, whereas Supplier $3(S 3)$ is the poorest pick, according to the computed results of both TODIM as well as PF-TODIM. This can be interpreted as $S 4$ has the best quality, as well as the highest values for sustainable criteria, including Green Design, CSR, and staff education.

\section{Sensitivity Analysis}

The sensitivity analysis in this article is done for both TODIM and Pythagorean fuzzy TODIM, which reveals the effects and stability of each of the methods. In this study, the criteria weights are calculated using rank sum weight method. To see how sensitive the system is, we performed our study on the modification of the attenuation factor $\theta$ as studied by Ren and Gou [55] and by Li et al. [60] who did their sensitivity analysis by taking randomly selected six different values of attenuation factor. We also tested sensitivity of our model by rearranging the weights for each criterion and thereby rearranging the rank of the criteria we utilized in the rank sum weight approach. We analysed how weight adjustments can impact the rankings on our model when decision makers provide their choice of ranks while calculating the criteria weights. The sensitivity is displayed using the heatmap representation approach. We have around a 1000 data points for each test performed. This large amount of data cannot be effectively summarised by bar charts. Therefore, heatmaps are chosen as an effective means of conveying the essential information collected through the experiment at a glance. The ranks that appear more frequently in this scheme are darker in color than the ranks that appear less frequently, which are lighter in color. Black is the darkest color or color of most frequently occurring ranks, whereas white is the lightest, that is, no occurrence of rank has taken place.

Figures 1 and 2 show how sensitive the model would be if TODIM for crisp sets had been used instead of Pythagorean fuzzy TODIM. Figure 1 depicts a change in ranking for three of the alternatives, namely $S 1, S 3$, and $S 5$, because of a change in attenuation factor. The rankings for the other three options, on the other hand, remain unchanged. Due to change in criteria weight, Figure 2 illustrates a change in rank for the same alternatives from Figure 1. Consequently, Supplier $4(S 4)$ is the most sustainable supplier, whereas Supplier 2 (S2) is the least sustainable of all.

As can be seen from the heatmap representation in Figures 3 and 4, the sensitivity analysis for Pythagorean fuzzy TODIM is stable. Changing the attenuation factor from 1 to 100 with a step size of 0.1 results in a total of 1001 observations with no change in rank for any of the alternatives. This indicates that the model is relatively stable and less susceptible to parameter (attenuation factor $\theta$ ) changes. As a result, decision makers, and other stakeholders may depend on the ranking we established for suppliers using Pythagorean fuzzy TODIM. Moving to Figure 4, we have checked the change in ranks of the alternatives with change in criteria weights. Also, we can observe that only for the alternatives $S 3$ and $S 5$, there are light grey dots, which means at the rank 5 and rank 6, where the grey dots appear, the alternatives have shown change for a certain changed weight shuffle. The frequency of these new positions is negligible 
TABLE 7: $\delta$ matrix for fuzzy TODIM.

\begin{tabular}{lcccccc}
\hline & $S 1$ & $S 2$ & $S 3$ & $S 4$ & $S 5$ & \multicolumn{2}{c}{$S 6$} \\
\hline$S 1$ & 0.000000 & 0.622632 & 1.094783 & -2.526386 & 0.762338 & -1.440690 \\
$S 2$ & -2.957800 & 0.000000 & 0.245667 & -4.921384 & -0.010759 & -4.309130 \\
S3 & -3.595614 & -1.408338 & 0.000000 & -5.321140 & -1.238177 & -4.794761 \\
$S 4$ & 0.701042 & 1.363427 & 1.498947 & 0.000000 & 1.500441 & -0.002496 \\
S5 & -3.192777 & -0.563682 & 0.074355 & -5.163070 & 0.000000 & -4.569714 \\
S6 & -0.463511 & 1.099182 & 1.285355 & -1.143332 & 1.269214 & 0.000000 \\
\hline
\end{tabular}

TABLE 8: Ratings using fuzzy TODIM.

\begin{tabular}{lr}
\hline & $\xi_{i}$ \\
\hline$S 1$ & 0.694264 \\
S2 & 0.205637 \\
S3 & 0.000000 \\
S4 & 1.000000 \\
S5 & 0.137406 \\
S6 & 0.859265 \\
\hline
\end{tabular}

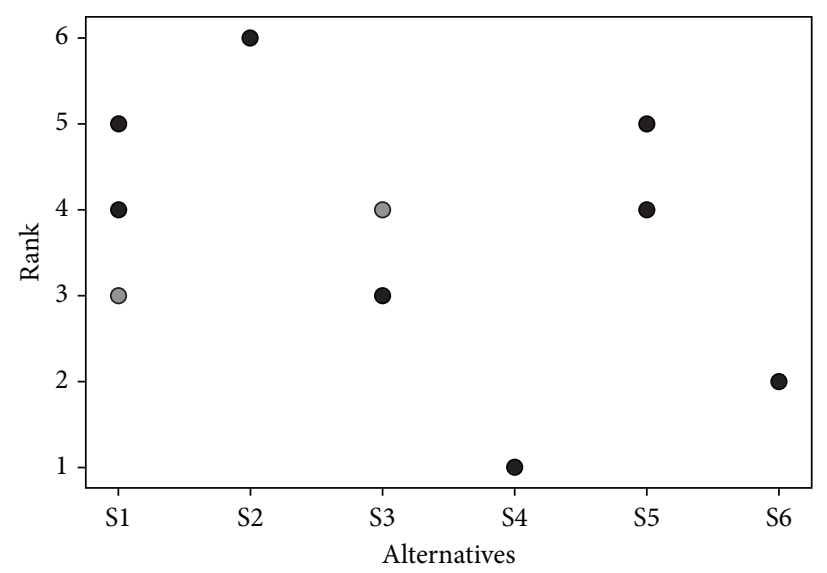

FIgURE 1: Rankings heatmap for regular TODIM by varying $\theta$.

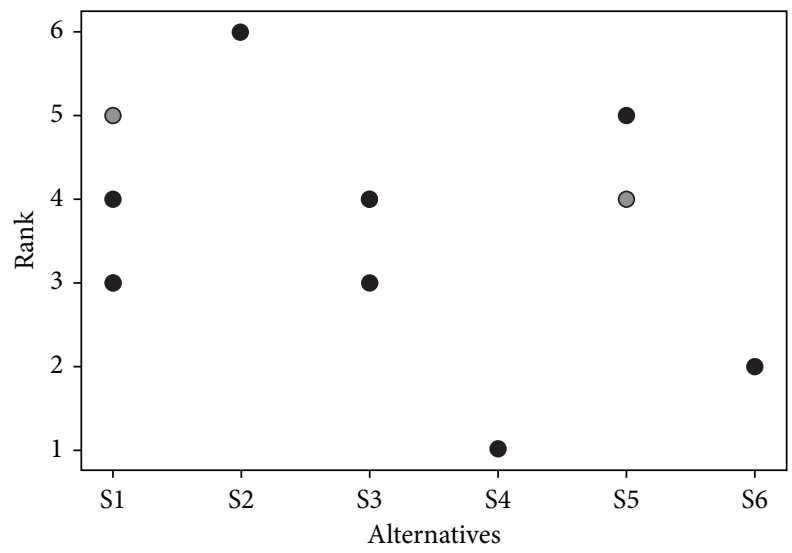

FIGURE 2: Rankings heatmap for regular TODIM by shuffling weights. 


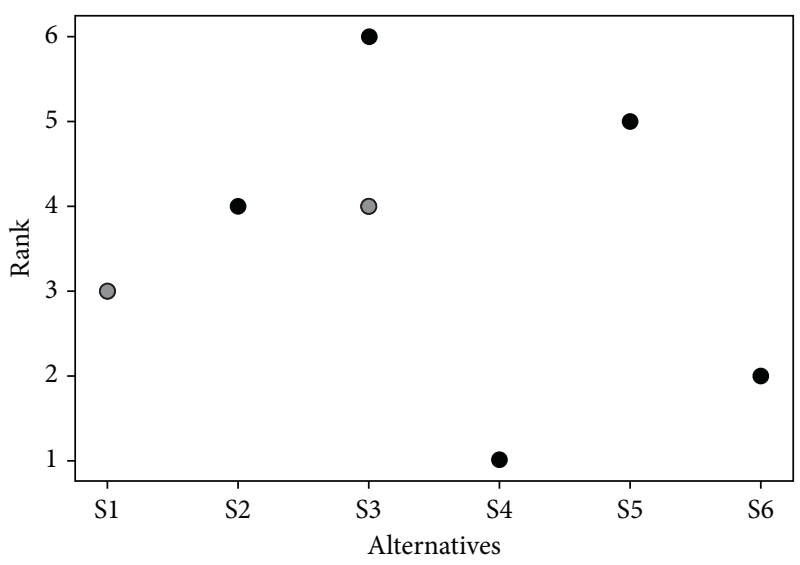

FIgURE 3: Rankings heatmap for fuzzy TODIM by varying $\theta$.

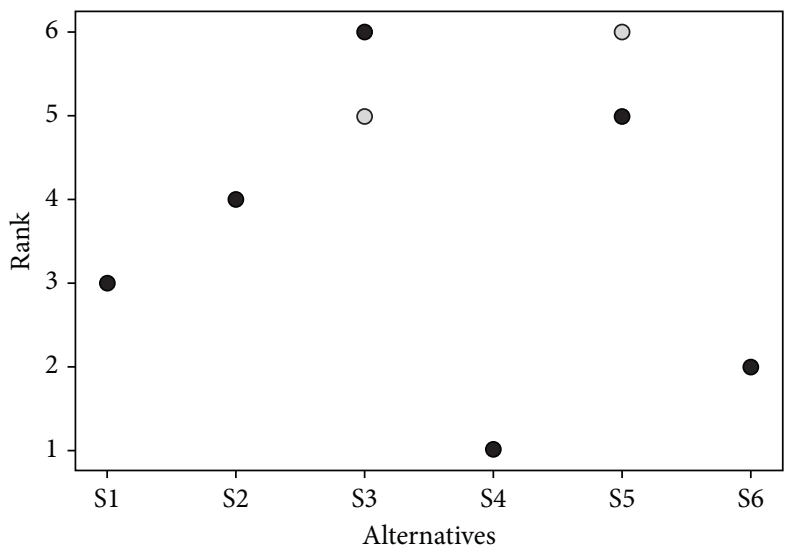

FIgURE 4: Rankings heatmap for fuzzy TODIM by shuffling weights.

compared with the main ranks due to their color being much lighter. The final rankings of PF-TODIM are a bit more dependable and resilient than TODIM for crisp set, as proved by sensitivity analysis. As a result, decision makers should rely on the PF-TODIM rankings.

\section{Conclusion}

As we have noted, according to the computed findings of both TODIM and PF-TODIM, Supplier 4 (S4) is the best supplier among the others, whereas Supplier 3 (S3) is the worst choice. $S 4$ has the greatest quality as well as the highest values for sustainable criteria, such as Green Design, CSR, and employee education. The sensitivity analysis showed that among roughly 1000 observations, the position of the best supplier does not vary with change in values of parameter (attenuation factor $\theta$ ) or weights of the criterion, demonstrating how consistent and reliable our model is. The list of rankings generated by varying $\theta$ and shuffling weights is available in the GitHub repository linked in the Supplementary Section. (Available here)

\section{Discussion and Future Scope}

Data studied in this article are acquired from Zolfani et al. [4] where they ranked the alternatives using Best Worst Method (BWM) and Combined Comprise Solution (CoCoSo) approach. After the application of the dataset in a fuzzy environment, which in our case is Pythagorean fuzzy TODIM, we have derived a different yet more stable and consistent result. The use of BWM has increased dramatically in a variety of sectors, including supplier selection and development as demonstrated by Rezaei et al. [61]. However, as Liang et al. [62] stated in their article, output-based consistency measurement in BWM cannot provide immediate feedback to a DM (decision maker), and only informs the DM about any inconsistencies in their assessments after the entire elicitation process has completed, which has been proven ineffective. As a result, we implemented the rank sum weight approach, which in general allows the decision maker with greater freedom in ranking the sustainability criteria for calculating the weights. We tested the sensitivity of our model to see how it would react if the order of the criteria changed. However, as 
seen in Figures 3 and 4, there is no discernible change in alternative rankings. We were inspired to make use of heatmap from an article by $\mathrm{Yu}$ et al. [63]. Also, we have not found any prior usages of heatmaps for sensitivity analysis especially in MCDM methods. We found the existing practice of using bar or line graphs to be inadequate. Therefore, in order to fulfil our requirements of conveying the results effectively, we have implemented heatmap.

Since 1997, decision support models in SSM or SSS have attracted a lot of attention in academics; however, there are still a lot of obstacles to overcome. Pythagorean fuzzy TODIM or PF-TODIM can be applied to places where decision makers are unsure about the data and can be implemented on various fields as Zimmer et al. [64] highlighted in industry-specific studies and comparisons, a comparison of widely used and seldom used modelling techniques, and the supplier qualifying process and transition to the final decision. Because of the simplicity of the computations, researchers may apply PFTODIM to a variety of different disciplines, such as risk prediction in economic aspects of sports organisations or in aspect of sustainable sports tourism studied by Yang et al. [65]. In the article of Kumar et al. [66], we can find some of the widely used MCDM approaches in sustainable, renewable, energy development, such as TOPSIS, VIKOR, PROMETHEE, and ELECTRE, which can be further compared with TODIM and PF-TODIM, to check the superiority of our model with respect to stability. Recent research by Ecer [67] focused on performance evaluation of battery electric cars included many MCDM algorithms, such as MARCOS, COCOSO, and others. TODIM or PF-TODIM may be used in such datasets, and further studies can be done to compare these MCDM methods to TODIM and perform sensitivity analysis.

Two important limitations of our model, that is PFTODIM, can be noted as follows:

(1) TODIM and its extensions, such as PF-TODIM, have higher time complexity for comparison, $O\left(m n^{2}\right)$ where $m$ is the number of criteria and $n$ is the number of candidates, whereas there exist other MCDM algorithms, such as TOPSIS, and its variants where the time complexity is relatively lower than TODIM.

(2) Although our model has a rank reversal problem, TODIM does not show a significant change in ranks when alternatives are added or deleted. According to some of our calculated observations, at most, two of the ranks are exchanged in this model. This is the limit. There may be situations, or for some dataset, we do not even have to deal with rank reversal, making our approach more reliable. However, additional research should be done to see whether this issue can be completely eliminated from the model, which would increase its overall value.

\section{Data Availability}

The Python source code along with the intermediate steps is available at the repository https:/github.com/ hungrybluedev/SustainabliltyFuzzyPTODIM.

\section{Conflicts of Interest}

The authors declare that they have no conflicts of interest.

\section{Supplementary Materials}

The Python source code along with the intermediate steps is available at the repository https:/github.com/ hungrybluedev/SustainabliltyFuzzyPTODIM. We have also provided the output generated by the Python code formatted into a single PDF file that includes all of the intermediate steps of the computation. The order in which the code and results are presented in the document is as follows: (1) TODIM ranking and (2) Pythagorean fuzzy TODIM ranking. (Supplementary Materials)

\section{References}

[1] A. H. I. Lee, H.-Y. Kang, C.-F. Hsu, and H.-C. Hung, "A green supplier selection model for high-tech industry," Expert Systems with Applications, vol. 36, no. 4, pp. 7917-7927, 2009.

[2] G. Büyükozkan and G. Çifçi, "Evaluation of the green supply chain management $€$ practices: a fuzzy ANP approach," Production Planning \& Control, vol. 23, no. 6, pp. 405-418, 2012.

[3] T. K. Bhatia, A. Kumar, S. S. Appadoo, Y. Gajpal, and M. K. Sharma, "Mehar approach for finding shortest path in supply chain network," Sustainability, vol. 13, no. 7, p. 4016, 2021.

[4] S. H. Zolfani, P. Chatterjee, and M. Yazdani, “A structured framework for sustainable supplier selection using a combined BWM-CoCoSo model," in Proceedings of the International Scientific Conference in Business, Management and Economics Engineering, pp. 797-804, Vilnius, Lithuania, May 2019.

[5] I. E. Nielsen, N. Banaeian, P. Golinska, H. Mobli, and M. Omid, "Green supplier selection criteria: from a literature review to a flexible framework for determination of suitable criteria," Logistics Operations, Supply Chain Management and Sustainability, Springer, Cham, Germany, pp. 79-99, 2014.

[6] O. El Mariouli and A. Abouabdellah, "A new model of supplier's selection for sustainable supply chain management," Advances in Science, Technology and Engineering Systems, vol. 4, no. 2, pp. 251-259, 2019.

[7] World Commission on Environment and Development, Report of the World Commission on Environment and Development: Our Common Future, Vol. 17, Encyclopedia, Chicago, IL, USA, 1987.

[8] A. Genovese, S. C. Lenny Koh, G. Bruno, and E. Esposito, "Greener supplier selection: state of the art and some empirical evidence," International Journal of Production Research, vol. 51, no. 10, pp. 2868-2886, 2013.

[9] K. Govindan, S. Rajendran, J. Sarkis, and P. Murugesan, "Multi criteria decision making approaches for green supplier evaluation and selection: a literature review," Journal of Cleaner Production, vol. 98, no. 1, pp. 66-83, 2015.

[10] M. Igarashi, L. De Boer, and A. M. Fet, "What is required for greener supplier selection? a literature review and conceptual model development," Journal of Purchasing and Supply Management, vol. 19, pp. 247-263, 2013.

[11] V. Batista Schramm, L. P. B. Cabral, and F. Schramm, "Approaches for supporting sustainable supplier selection-a 
literature review," Journal of Cleaner Production, vol. 273, Article ID 123089, 2020.

[12] P. Shalke, M. M. Paydar, and M. Hajiaghaei-Keshteli, "Sustainable supplier selection and order allocation through quantity discounts," International Journal of Management Science and Engineering Management, vol. 13, no. 1, pp. 20-32, 2018.

[13] A. Mohammed, "Towards a sustainable assessment of suppliers: an integrated fuzzy TOPSIS-possibilistic multi-objective approach," Annals of Operations Research, vol. 293, pp. 639-668, 2019.

[14] A. Memari, A. Dargi, M. R. Akbari Jokar, R. Ahmad, and A. R. Abdul Rahim, "Sustainable supplier selection: a multicriteria intuitionistic fuzzy TOPSIS method," Journal of Manufacturing Systems, vol. 50, pp. 9-24, 2019.

[15] C. Bai and J. Sarkis, "Integrating sustainability into supplier selection: a greybased TOPSIS analysis," Technological and Economic Development of Economy, vol. 24, no. 6, pp. 22022224, 2018.

[16] C. Bai and J. Sarkis, "Integrating sustainability into supplier selection with grey system and rough set methodologies," International Journal of Production Economics, vol. 124, no. 1, pp. 252-264, 2010.

[17] J. Li, H. Fang, and W. Song, "Sustainable supplier selection based on SSCM practices: a rough cloud TOPSIS approach," Journal of Cleaner Production, vol. 222, pp. 606-621, 2019.

[18] B. M. dos Santos, L. P. Godoy, and L. M. S. Campos, "Performance evaluation of green suppliers using entropy-TOPSIS-F," Journal of Cleaner Production, vol. 207, pp. 498-509, 2019.

[19] S. Luthra, K. Govindan, D. Kannan, S. K. Mangla, and C. P. Garg, "An integrated framework for sustainable supplier selection and evaluation in supply chains," Journal of Cleaner Production, vol. 140, pp. 1686-1698, 2017.

[20] N. Jain and A. R. Singh, "Sustainable supplier selection under must-be criteria through fuzzy inference system," Journal of Cleaner Production, vol. 248, Article ID 119275, 2020a.

[21] M. Zhao, G. Wei, C. Wei, and J. Wu, "TODIM method for interval-valued pythagorean fuzzy MAGDM based on cumulative prospect theory and its application to green supplier selection," Arabian Journal for Science and Engineering, vol. 46, no. 2, pp. 1899-1910, 2021.

[22] N. Jain, A. R. Singh, and R. K. Upadhyay, "Sustainable supplier selection under attractive criteria through FIS and integrated fuzzy MCDM techniques," International Journal of Sustainable Engineering, vol. 13, no. 6, pp. 441-462, 2020.

[23] N. Jain and A. R. Singh, "Sustainable supplier selection criteria classification for Indian iron and steel industry: a fuzzy modified Kano model approach," International Journal of Sustainable Engineering, vol. 13, no. 1, pp. 17-32, 2020 b.

[24] J. Qin, X. Liu, and W. Pedrycz, "An extended TODIM multicriteria group decision making method for green supplier selection in interval type-2 fuzzy environment," European Journal of Operational Research, vol. 258, no. 2, pp. 626-638, 2017.

[25] J. Sarkis, "Evaluating environmentally conscious business practices," European Journal of Operational Research, vol. 107, no. 1, pp. 159-174, 1998.

[26] M. R. Galankashi, C. Ali, S. Amin et al., "Prioritizing green supplier selection criteria using fuzzy analytical network process," Procedia CIRP, vol. 26, pp. 689-694, 2015.

[27] S. Khoshfetrat, M. R. Galankashi, and M. Almasi, "Sustainable supplier selection and order allocation: a fuzzy approach," Engineering Optimization, vol. 52, no. 9, pp. 1494-1507, 2020.
[28] M. Tavana, M. Yazdani, and D. Di Caprio, “An application of an integrated ANP-QFD framework for sustainable supplier selection," International Journal of Logistics Research and Applications, vol. 20, no. 3, pp. 254-275, 2017.

[29] M. O. Okwu and L. K. Tartibu, "Sustainable supplier selection in the retail industry: a TOPSIS-and ANFIS-based evaluating methodology," International Journal of Engineering Business Management, vol. 12, 2020.

[30] S. A. Hoseini, A. Fallahpour, K. Y. Wong, A. Mahdiyar, M. Saberi, and S. Durdyev, "Sustainable supplier selection in construction industry through hybrid fuzzy-based approaches," Sustainability, vol. 13, no. 3, p. 1413, 2021.

[31] G. Akman, "Evaluating suppliers to include green supplier development programs via fuzzy c-means and VIKOR methods," Computers \& Industrial Engineering, vol. 86, 2014.

[32] M. Almasi, S. Khoshfetrat, and M. R. Galankashi, "Sustainable supplier selection and order allocation under risk and inflation condition," IEEE Transactions on Engineering Management, vol. 68, no. 3, 2019.

[33] L. F. A. M. Gomes and L. A. D. Rangel, “An application of the TODIM method to the multicriteria rental evaluation of residential properties," European Journal of Operational Research, vol. 193, no. 1, pp. 204-211, 2009.

[34] R.-J. Mao, J.-X. You, C.-Y. Duan, and L.-N. Shao, "A heterogeneous MCDM framework for sustainable supplier evaluation and selection based on the IVIF-TODIM method," Sustainability, vol. 11, no. 18, p. 5057, 2019.

[35] A. A. Khamseh, "A time-dependent sustainable-flexible supplier selection considering uncertainty and TODIM method in Iranian dairy industries," Global Journal of Flexible Systems Management, vol. 22, no. 2, pp. 113-126, 2021.

[36] C. Bai, S. Kusi-Sarpong, H. Badri Ahmadi, and J. Sarkis, "Social sustainable supplier evaluation and selection: a group decision-support approach," International Journal of Production Research, vol. 57, no. 22, pp. 7046-7067, 2019.

[37] Z.-P. Tian, H.-Y. Zhang, J.-Q. Wang, and T.-L. Wang, "Green supplier selection using improved TOPSIS and best-worst method under intuitionistic fuzzy environment," Informatica, vol. 29, no. 4, pp. 773-800, 2018.

[38] M. Abdel-Baset, V. Chang, A. Gamal, and F. Smarandache, "An integrated neutrosophic ANP and VIKOR method for achieving sustainable supplier selection: a case study in importing field," Computers in Industry, vol. 106, pp. 94-110, 2019.

[39] N. Bojković, I. Anić, and S. Pejčić-Tarle, "One solution for cross-country transport-sustainability evaluation using a modified ELECTRE method," Ecological Economics, vol. 69, no. 5, pp. 1176-1186, 2010.

[40] I. Majdi, "Comparative evaluation of PROMETHEE and ELECTRE with application to sustainability assessment," Doctoral Dissertation, Concordia University, Montreal, Canada, 2013.

[41] S. Guo and H. Zhao, "Optimal site selection of electric vehicle charging station by using fuzzy TOPSIS based on sustainability perspective," Applied Energy, vol. 158, pp. 390-402, 2015.

[42] R. Micale, A. Giallanza, G. Russo, and G. La Scalia, "Selection of a sustainable functional pasta enriched with opuntia using ELECTRE III methodology," Sustainability, vol. 9, no. 6, p. 885, 2017.

[43] A. Awasthi, K. Govindan, and S. Gold, "Multi-tier sustainable global supplier selection using a fuzzy AHP-VIKOR based approach," International Journal of Production Economics, vol. 195, pp. 106-117, 2018. 
[44] L. Chen and J. Ren, "Multi-attribute sustainability evaluation of alternative aviation fuels based on fuzzy ANP and fuzzy grey relational analysis," Journal of Air Transport Management, vol. 68, pp. 176-186, 2018.

[45] L. Suganthi, "Multi expert and multi criteria evaluation of sectoral investments for sustainable development: an integrated fuzzy AHP, VIKOR/DEA methodology," Sustainable Cities and Society, vol. 43, pp. 144-156, 2018.

[46] C.-N. Wang, V. T. Nguyen, H. T. N. Thai, N. N. Tran, and T. L. A. Tran, "Sustainable supplier selection process in edible oil production by a hybrid fuzzy analytical hierarchy process and green data envelopment analysis for the SMEs food processing industry," Mathematics, vol. 6, no. 12, p. 302, 2018.

[47] M. Nilashi, A. Mardani, H. Liao, H. Ahmadi, A. A. Manaf, and W. Almukadi, "A hybrid method with TOPSIS and machine learning techniques for sustainable development of green hotels considering online reviews," Sustainability, vol. 11, no. 21, p. 6013, 2019.

[48] J. Tang, H.-l. Zhu, Z. Liu, F. Jia, and X.-X. Zheng, "Urban sustainability evaluation under the modified TOPSIS based on grey relational analysis," International Journal of Environmental Research and Public Health, vol. 16, no. 2, p. 256, 2019.

[49] Y. Du, D. Zhang, and Y. Zou, "Sustainable supplier evaluation and selection of fresh agricultural products based on IFAHPTODIM model," Mathematical Problems in Engineering, vol. 2020, Article ID 4792679, 15 pages, 2020.

[50] J.-J. Peng, C. Tian, W.-Y. Zhang, S. Zhang, and J.-Q. Wang, "An integrated multi-criteria decision-making framework for sustainable supplier selection under picture fuzzy environment," Technological and Economic Development of Economy, vol. 26, no. 3, pp. 573-598, 2020.

[51] Y. Wu, M. Liao, M. Hu et al., "A decision framework of lowspeed wind farm projects in hilly areas based on DEMATELentropy-TODIM method from the sustainability perspective: a case in China," Energy, vol. 213, Article ID 119014, 2020.

[52] M. Alimohammadlou and Z. Khoshsepehr, "Investigating organizational sustainable development through an integrated method of interval-valued intuitionistic fuzzy AHP and WASPAS," Environment, Development and Sustainability, vol. 2021, pp. 1-32, 2021.

[53] C. Tang, D. Xu, and N. Chen, "Sustainability prioritization of sewage sludge to energy scenarios with hybrid-data consideration: a fuzzy decision-making framework based on full consistency method and fusion ranking model," Environmental Science and Pollution Research, vol. 28, no. 5, pp. 5548-5565, 2021.

[54] R. R. Yager, "Pythagorean fuzzy subsets," in Proceedings of the 2013 Joint IFSA World Congress and NAFIPS Annual Meeting (IFSA/NAFIPS), pp. 57-61, IEEE, Edmonton, Canada, June 2013.

[55] P. Ren, Z. Xu, and X. Gou, "Ppythagorean fuzzy TODIM approach to multi-criteria decision making," Applied Soft Computing Journal, vol. 42, 2015.

[56] A. Tversky and D. Kahneman, "Advances in prospect theory: cumulative representation of uncertainty," Journal of Risk and Uncertainty, vol. 5, no. 4, pp. 297-323, 1992.

[57] N. Zoraghi, M. Amiri, G. Talebi, and M. Zowghi, “A fuzzy MCDM model with objective and subjective weights for evaluating service quality in hotel industries," Journal of Industrial Engineering International, vol. 9, no. 1, p. 38, 2013.

[58] E. Roszkowska, "Rank ordering criteria weighting methods-a comparative overview," Optimum Studia Ekonomiczne NR, vol. 5, no. 65, pp. 14-33, 2013.
[59] W. G. Stillwell, D. A. Seaver, and W. Edwards, “A comparison of weight approximation techniques in multiattribute utility decision making," Organizational Behavior \& Human Performance, vol. 28, no. 1, pp. 62-77, 1981.

[60] M. Li, C. Wu, and L. Zhang, "An intuitionistic fuzzy-TODIM method to solve distributor evaluation and selection problem," International Journal of Simulation Modelling, vol. 14, no. 3, pp. 511-524, 2015.

[61] J. Rezaei, W. S. van Roekel, and L. Tavasszy, "Measuring the relative importance of the logistics performance index indicators using best worst method," Transport Policy, vol. 68, pp. 158-169, 2018.

[62] F. Liang, M. Brunelli, and J. Rezaei, "Consistency issues in the best worst method: measurements and thresholds," Omega, vol. 96, Article ID 102175, 2020.

[63] C.-S. Yu, C.-H. Lin, Y.-J. Lin et al., "Clustering heatmap for visualizing and exploring complex and high-dimensional data related to chronic kidney disease," Journal of Clinical Medicine, vol. 9, no. 2, p. 403, 2020.

[64] K. Zimmer, M. Fröhling, and F. Schultmann, "Sustainable supplier management-a review of models supporting sustainable supplier selection, monitoring and development," International Journal of Production Research, vol. 54, no. 5, pp. 1412-1442, 2016.

[65] J.-J. Yang, Y.-C. Chuang, H.-W. Lo, and T.-I. Lee, "A twostage MCDM model for exploring the influential relationships of sustainable sports tourism criteria in Taichung city," International Journal of Environmental Research and Public Health, vol. 17, no. 7, p. 2319, 2020.

[66] A. Kumar, B. Sah, A. R. Singh et al., "A review of multi criteria decision making (MCDM) towards sustainable renewable energy development," Renewable and Sustainable Energy Reviews, vol. 69, pp. 596-609, 2017.

[67] F. Ecer, "A consolidated MCDM framework for performance assessment of battery electric vehicles based on ranking strategies," Renewable and Sustainable Energy Reviews, vol. 143, Article ID 110916, 2021. 